\title{
Sago Waste Based Activated Carbon Film as an Electrode Material for Electric Double Layer Capacitor
}

\author{
H. Aripin ${ }^{*}, 1$ L. Lestari ${ }^{1}$, D. Ismail ${ }^{2}$ and S. Sabchevski ${ }^{3}$ \\ ${ }^{I}$ Department of Physics, Faculty of Mathematics and Natural Sciences, Haluoleo University, Kampus Bumi Tridharma \\ Anduonohu Kendari 93232, Indonesia \\ ${ }^{2}$ Department of Chemistry, Faculty of Mathematics and Natural Sciences, Haluoleo University, Kampus Bumi \\ Tridharma Anduonohu Kendari 93232, Indonesia \\ ${ }^{3}$ Lab. Electron Beam Technologies, Institute of Electronics of the Bulgarian Academy of Sciences, 72 Tzarigradsko \\ Shose Blvd., 1784 Sofia, Bulgaria
}

\begin{abstract}
In this feasibility study a novel prospective electrode material for electric double layer capacitors (EDLC) has been investigated. This promising material is activated carbon (AC) film produced using sago waste as a precursor. Important parameters of the technological process are the $\mathrm{KOH}$ to charcoal ratio and the content of the polytetrafluoroethylene (PTFE) binder. The influence of these parameters on the microtexture and pore structure and on the electrochemical characteristics of the AC films has been studied in detail. The measured specific surface area (SSA) of the samples is in the range from 212 to $1498 \mathrm{~m}^{2} / \mathrm{g}$. It has been found that the presence of micropores increases the specific capacity while the presence of the mesopores acts in the opposite direction, because these mesopores are too wide in diameter for aqueous electrolyte. The specific capacitance of the studied samples has been found to be in the range from 16 to $64 \mathrm{~F} / \mathrm{g}$.
\end{abstract}

Keywords: Sago waste, activated carbon, KOH ratio, PTFE content, specific surface area, pore structure, specific capacitance.

\section{INTRODUCTION}

Carbon, in all its allotropic forms, is one of the most widely used materials and has countless applications in various industrial processes and technical devices [1-3]. Among them are those related to the development of advanced energy storage systems with high energy and power density, e.g. fuel cells, lithium ion batteries and electrochemical capacitors. A promising and actively studied variety of the latter is the electrical/electrochemical double layer capacitor (EDLC) also known as "super-capacitor" or "ultra-capacitor", which is characterized by energy density in the range of $1-10 \mathrm{Wh} / \mathrm{kg}$ and power density of $1000-10000$ $\mathrm{W} / \mathrm{kg}$. Such advantageous parameters together with many other technological and economical benefits (high number of charge-discharge cycles; faster charge-discharge; absence of disposable parts and environmentally harmful components; high efficiency up to $98 \%$; low thermal load; safety and reliability) substantiate the concept of replacement of the batteries as a storage media by EDLC in many systems where traditionally batteries are used (e.g. hybrid electric vehicles, power back-up systems, UPS etc.).

The key components of each EDLC are the electrodes made of carbon with high degree of porosity and, correspondingly, with high specific surface area (SSA). The overall performance of the entire EDLC system depends

*Address correspondence to this author at the Department of Physics, Faculty of Mathematics and Natural Sciences, Haluoleo University, Kampus Bumi Tridharma Anduonohu Kendari, Indonesia; Tel: +62-401-394108; Fax: +62-401-390006; E-mal: aripin01@yahoo.com strongly on the parameters of the electrode material. Some of the potentially appropriate materials are various grades of activated carbon (AC) [4], carbonized polymers [5, 6], aerogels [7], carbon fibers [8], and nano-tubes [9, 10]. Among them, AC is a natural choice since it is characterized by high SSA (up to $3000 \mathrm{~m}^{2} / \mathrm{g}$ ). The detailed analysis [1113] of the experimental data however reveals the role of the micro porosity and shows that AC with characteristic sizes of the pores less than $2 \mathrm{~nm}$ are not appropriate because the ionic motion in such narrow channels is slower and prohibits the percolation of the electrolyte. Similar adverse effects can be caused also by various irregularities of the pores as well as by the absence of connections between them (isolated pores). Another critical issue is the role of the binder, which holds together the activated carbon particles as a single mechanical unit and ensures a resistance against etching by the electrolyte solution but also tends to block the pores. Most of the problems mentioned above however can be solved selecting an appropriate carbonaceous precursor.

In the present study we consider as such precursor a material that is abundant in Indonesia, namely the industrial waste from the processing of sago (starch from Metroxylon sagu also known as sago palm). Indonesia exports between 200000 and 260000 tons of sago flour annually but the residues from its production tend to be discharged to the rivers. These residues, which are largely composed of celluloses and lignin [14], are both a waste and a pollutant. Their chemical composition suggests that they possess some potential as electrochemical materials, because of their porous structure. In this paper we report the results of the research focused on both the preparation of AC films based 
on sago waste and on the investigation of their electrochemical properties. We discuss also the importance of the technological parameters such as the potassium hydroxide $(\mathrm{KOH})$ to charcoal ratio and the concentration of the polytetrafluoroethylene (hereafter PTFE) binder and their influence on the capacitance of EDLC.

\section{EXPERIMENTAL SET-UP}

\section{Preparation of the Studied Samples}

Sago wastes that consist of fine and coarse "hampas" (solid residue which is left behind after the starch has been washed out) were obtained from the sago processing plant in Kendari, Indonesia. The material for the samples was selected manually, cleaned and dried in an oven at temperature of $105^{\circ} \mathrm{C}$ for 24 hours. Afterwards, the samples were placed into a porcelain container and carbonized at $350^{\circ} \mathrm{C}$ for one hour in a muffle furnace. The obtained charcoal (CS) was cooled down to room temperature and ground using a jar mill to pass through a $70-150 \mu \mathrm{m}$ sieve. Two different activation methods were applied. The first one was a chemical activation process consisting of $\mathrm{KOH}$ impregnation followed by carbonization at high temperature $\left(500-900^{\circ} \mathrm{C}\right)$ for several hours. The second one was a twostep physical activation process. In the first step a carbonization of the raw material at temperature less than $700{ }^{\circ} \mathrm{C}$ was carried out. The second step converts the carbonized product to a porous AC having high SSA by heating to higher temperature $\left(800-1000{ }^{\circ} \mathrm{C}\right)$. In the case of the chemical activation the charcoals were suspended in a concentrated solution of $\mathrm{KOH}$ and four types of samples were prepared by varying the weight ratio of $\mathrm{KOH}$ and charcoal. They correspond to ratios equal to $1: 1,2: 1,3: 1$ and 4:1 respectively. Then the samples were heated at the activation temperature of $800^{\circ} \mathrm{C}$ for one hour in a horizontal furnace using nitrogen flow at a speed of $800 \mathrm{ml} / \mathrm{min}$. Each ACs sample was labeled as SCK1, SCK2, SCK3 and SCK4, respectively. The samples were washed by de-ionized water, dried at $110^{\circ} \mathrm{C}$ for 3 hours and then stored in a desiccator for further studies.

For preparing an electrode of EDLC, $0.95 \mathrm{~g}$ of the SC sample was mixed with $5 \%$ of PTFE powder following the procedures described elsewhere [15]. PTFE powder was used as a binder and was mixed with a solution of isopropanol and deionised water with a weight ratio of 1:5. Acetone, in a weight ratio of $2: 1$ with respect to the SC sample, was added to this solution to allow a good homogenization of the binder suspension. The mixture was then rolled to form flexible film. The SC film was mounted on an aluminum foil using hot hydraulic press at pressure of 5 tons and temperature of $321^{\circ} \mathrm{C}$, then cooled down using cool hydraulic press at speed of cooling of 15 degree per minute. The obtained thickness and area of the SC film of the sample SC5 was $400 \mu \mathrm{m}$ and $10 \mathrm{x} 10 \mathrm{~cm}^{2}$, respectively. The same procedure was carried out for SCK1, SCK2, SCK3 and SCK 4 and each of the samples was labeled as CP51, CP52, CP53 and CP54, respectively. Further, a compound corresponding to SCK4 sample (i.e. with $\mathrm{KOH}$ to charcoal ratio 4:1) was mixed with varying content of the PTFE powder. The samples with PTFE content of 10\%, 20\%, 30\% and $40 \%$ were labeled accordingly as CP104, CP204, CP304 and CP404.
Apparatus, Method and Procedures used in the Measurements

The porosity and the surface properties of SC, SCK and CP samples were investigated by the nitrogen adsorptiondesorption method using an automatic volumetric sorption analyzer, namely Quantachrome, Nova-1000. The SC and SCK samples were measured in the form of powder while the $\mathrm{CP}$ samples were measured as $\mathrm{AC}$ films. Prior to the measurements, the samples were degassed at $200^{\circ} \mathrm{C}$ for 5 hours. The SSA values were calculated by applying the Brunauer-Emmett-Teller (BET) model $[16,17]$. The total pore volume was obtained from the volume of the absorbed nitrogen. On the other hand, the micropore volume was calculated using the Dubinin-Radushkevich (DR) equation [18]. The surface morphology of the CP sample was then examined by a scanning electron microscope (SEM) JOEL JSM-6400. The images were taken at a magnification of $2000 \mathrm{x}$ at $10 \mathrm{kV}$. The Fourier transformed infra-red (IR) spectra were recorded using IRPrestige-21 in the $400-3900$ $\mathrm{cm}^{-1}$ wave number range by the $\mathrm{KBr}$ method.

In the electrochemical experiments, a two-electrode cell was used to measure the capacitance. Both the charging and the discharging capacity of the capacitor were obtained by means of a two-terminal measurement [19]. In the experiment, aluminum foil plates were attached as current collectors to the sheet-shaped film samples with dimensions $2 \times 2 \mathrm{~cm}^{2}$. The test cell was fabricated using two square electrodes of the same type and size separated by a porous polypropylene membrane inserted between them. A $30 \mathrm{wt} . \%$ $\mathrm{H}_{2} \mathrm{SO}_{4} / \mathrm{H}_{2} \mathrm{O}$ or $1 \mathrm{M}$ of $\mathrm{LiClO}_{4} / \mathrm{PC}$ was used as an aqueous and as an organic electrolyte, respectively. The cell was charged at a constant voltage of $0.9 \mathrm{~V}$ for 10 minutes and the capacitance was obtained from the variation of the discharge current density up to $200 \mathrm{~mA} / \mathrm{cm}^{2}$.

\section{EXPERIMENTAL RESULTS AND DISCUSSION}

Fig. (1) shows the Fourier Transform Infra-Red (FTIR) spectra of the activated carbon (SCK) prepared at different $\mathrm{KOH}$ ratios. They were recorded from 400 to $3900 \mathrm{~cm}^{-1}$. The FTIR analysis was carried out on powder samples in order to investigate the chemical reactivity of functional groups at the surface of SCK that occurred at different $\mathrm{KOH}$ ratios. The FTIR spectrum of the sago hampas was similar to that of baggase [20], which is a type of lignocellulosic material. The absorption band observed at about $3536 \mathrm{~cm}^{-1}$ was attributed to the $\mathrm{O}-\mathrm{H}$ stretching vibrations in hydroxyl groups. The strong characteristic peak of oxygen-rich SCK at $1709 \mathrm{~cm}^{-1}$ is attributed to the stretching vibration of the carboxyl group $\mathrm{C}=\mathrm{O}$ bond in carboxylic acid for all values of the $\mathrm{KOH}$ ratio $[12,21]$. The oxygenated group concentration increases with increasing the KOH ratio from 1 to 4 . The band at $1392 \mathrm{~cm}^{-1}$ could be attributed to $\mathrm{O}-\mathrm{H}$ bending of carboxylic acid. The $\mathrm{C}-\mathrm{O}$ stretching of carboxylic acid at $1223 \mathrm{~cm}^{-1}$ disappeared for SCK when compared to SC.

The nitrogen adsorption-desorption method was employed to measure the surface properties of the SC and SCK samples. Fig. (2) shows $\mathrm{N}_{2}$ adsorption isotherms of the SC and SCK samples at $77 \mathrm{~K}$. According to the classification of the International Union of Pure and Applied Chemistry (IUPAC) [22], these adsorption isotherms for all samples 


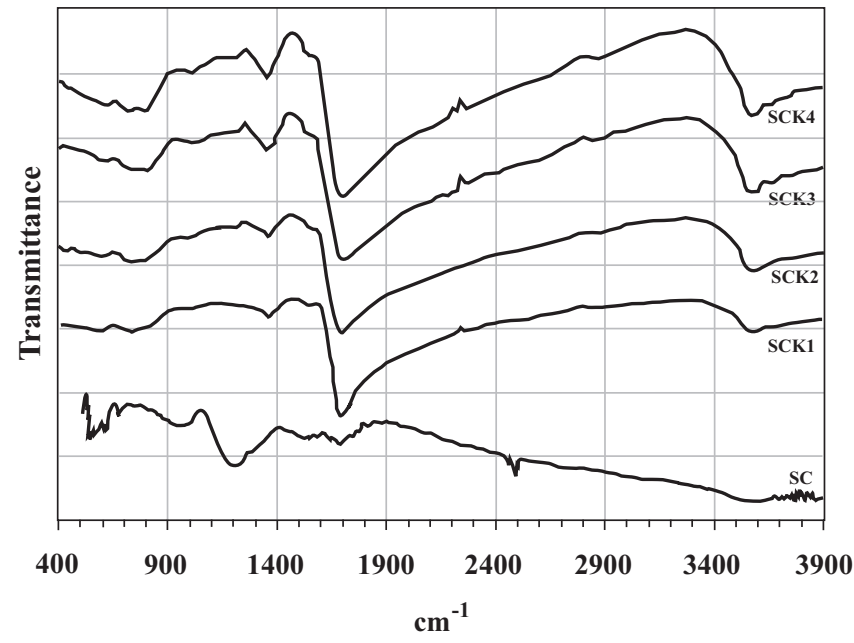

Fig. (1). FTIR spectra of the sago hampas char (SC) and $\mathrm{KOH}$ activated carbon at different $\mathrm{KOH}$ and char ratio. The samples with ratios equal to $1: 1,2: 1,3: 1$ and $4: 1$ are labeled as SCK1, SCK2, SCK3 and SCK4, respectively.

correspond to the Type I micro-pores. At very low relative pressure $(\mathrm{P} / \mathrm{Po}<1)$, the amounts of adsorption are high which can be explained by the filling effect of the micropores, except in the case of SC, which is a nonporous material. In this region the amount of adsorbed $\mathrm{N}_{2}$ increases as a function of the $\mathrm{KOH}$ to charcoal ratio. It was found that the increase of adsorbed $\mathrm{N}_{2}$ after $\mathrm{P} / \mathrm{Po}=0.1$ is small due to the capillary condensation of $\mathrm{N}_{2}$ in the mesopores.

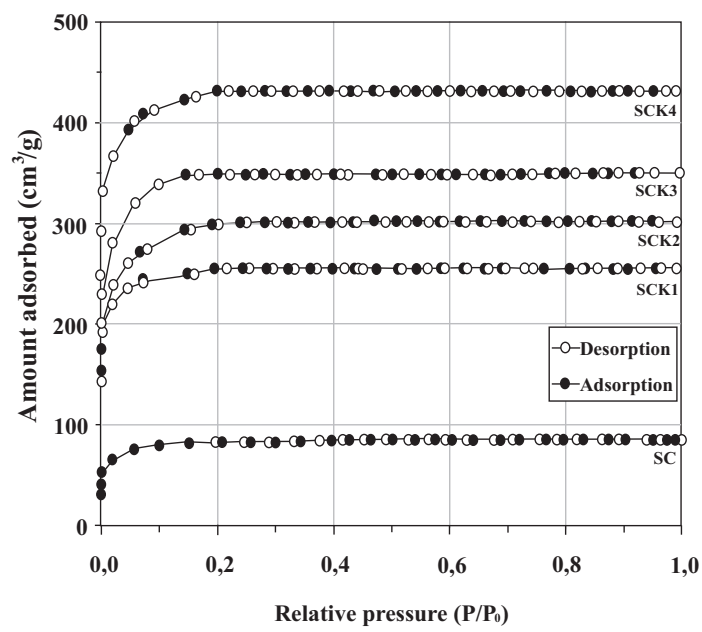

Fig. (2). $\mathrm{N}_{2}$ adsorption-desorption isotherms of the SCK at $77 \mathrm{~K}$. The labels SCK1, SCK2, SCK3 and SCK4 correspond to samples with weight ratio of $\mathrm{KOH}$ and charcoal equal to $1: 1,2: 1,3: 1$ and 4:1 respectively.

Table 1 shows the pore characteristics of the SC and SCK samples and how they change with the variation of the $\mathrm{KOH}$ ratio. It can be seen that the total $\left(S_{\mathrm{BET}}\right)$, micropore $\left(S_{\mathrm{mi}}\right)$ and mesopore $\left(S_{\mathrm{me}}\right)$ specific surface areas (SSA) of the SCK gradually increase when the $\mathrm{KOH}$ ratio is increasing from 1 to 4 . Similarly, the total pore volumes were found to increase with increasing the $\mathrm{KOH}$ ratio. According to the general standard, pore with diameters less than $2 \mathrm{~nm}$ are classified as micropore, those with diameters from 2 to 50 $\mathrm{nm}$ are mesopores, and those with diameters larger than 50 $\mathrm{nm}$ are macropores. Further, the micropore is classified as supermicropore (pore with diameter between $0.7-2 \mathrm{~nm}$ ) and ultramicropore (pore with diameters less than $0.7 \mathrm{~nm}$ ). Hence, the SC was composed of ultramicropores, while the SCKs have a wide distribution of micropores and mesopores. As it can be seen in the Table $\mathbf{1}$, the micropores occupy a greater portion of the total pore volume in the SCK and the percentage of the mesopores volume increase with increasing the $\mathrm{KOH}$ ratio. The reason why the addition of $\mathrm{KOH}$ ratio causes an increase of the porosity is explained as follows. It can be understood by considering the mechanism which explains the transformations of carbonized chars soaked in a $\mathrm{KOH}$ solution. By increasing the ratios of $\mathrm{KOH}$ from 1 to 4 , the amount of the porosity of the SCKs also increases. During the soaking of the carbonized char in a small amount of $\mathrm{KOH}$ most of the $\mathrm{KOH}$ was seeped into the interior of the chars and the surface coating of $\mathrm{KOH}$ in this case is incomplete. Thus, the activation of $\mathrm{KOH}$ creates smaller pores on the surface of the carbonized chars. During the soaking of the carbonized chars in $\mathrm{KOH}$ of greater concentration, the surface of the char was coated by a thin film of $\mathrm{KOH}$ while the interior of the sample was filled by $\mathrm{KOH}$ completely [23]. In this case both the surface and the interior of the chars react more actively with $\mathrm{KOH}$, thus the pores of the surface and of the interior become larger. Additionally this leads to an increase in the amount of the micropores. A further reaction between $\mathrm{KOH}$ and carbonized chars of the microporous structure formed at a previous stage can destroy the microporous structure and enlarge the pore. This confirms the observation that the higher the concentration of $\mathrm{KOH}$ the bigger is the number of the micropores and of the mesopores produced as a result of the reaction. Table 2 shows the pore and the specific capacitance characteristics of the SC and SCK samples with PTFE content of $5 \%$. The comparison of data presented in Tables 1 and 2 shows that there is a small decrease of the SSA and pore size distribution (PSD) when the SC and the SCK samples are mixed by $5 \%$ of PTFE. It is apparent that the increase in the micropores SSA is smaller compared to the increase of the mesopores SSA when going from one concentration of $\mathrm{KOH}$ to another one in the series.

Fig. (3) shows the variation of the specific capacitances in 30 wt. $\% \mathrm{H}_{2} \mathrm{SO}_{4} / \mathrm{H}_{2} \mathrm{O}$ and $1 \mathrm{M} \mathrm{LiClO}_{4} / \mathrm{PC}$ as a function of the discharge current density for different values of the $\mathrm{KOH}$ ratio for the CP5 samples. The specific capacitance of CP5 increases with increasing of $\mathrm{KOH}$ ratio in $\mathrm{H}_{2} \mathrm{SO}_{4}$ or $\mathrm{LiClO}_{4}$ electrolyte. The specific capacitance gradually increases from $16-64 \mathrm{~F} / \mathrm{g}$ for $\mathrm{KOH}$ ratio in the interval $1-4$ and PTFE content of 5\%. It should be underlined that the specific capacitance of the CP5 samples is much higher than that of the SC5 sample. We assume that in the case of the SC5 sample, the size of the pores can be classified as ultramicropores and therefore only a small amount of the electrolyte ions is able to penetrate (diffuse) into the narrow pores and can be absorbed. It should also be noted however that such increase is larger in $\mathrm{LiClO}_{4}$ electrolyte than in $\mathrm{H}_{2} \mathrm{SO}_{4}$ electrolyte at low discharge current density $(<50$ $\left.\mathrm{mA} / \mathrm{cm}^{2}\right)$. This result can be related to the difference between the ion sizes of the electrolyte and the pore diameter of SCKs. It was reported that $\mathrm{H}_{2} \mathrm{SO}_{4}$ electrolyte has very small size of $\mathrm{H}^{+}$ion and about $0.533 \mathrm{~nm}$ for the sulfide ion, while the $\mathrm{LiClO}_{4}$ electrolyte has ions sizes of about $1.19 \mathrm{~nm}$ for $\mathrm{Li}^{+}$ion and $0.49 \mathrm{~nm}$ for $\mathrm{ClO}_{4}{ }^{-}$ion $[24,25]$. The $\mathrm{H}_{2} \mathrm{SO}_{4}$ 
Table 1. The Pore Characteristics of the SC and SCK Samples Having Different KOH Ratio

\begin{tabular}{|c|c|c|c|c|c|c|c|c|c|}
\hline Sample Type & $S_{\text {BET }}\left(\mathbf{m}^{2} / \mathbf{g}\right)$ & $S_{\text {mi }}\left(\mathbf{m}^{2} / \mathbf{g}\right)$ & $S_{\text {me }}\left(\mathbf{m}^{2} / \mathbf{g}\right)$ & $V_{\text {total }}\left(\mathbf{c m}^{3} / \mathbf{g}\right)$ & $V_{\text {mi }}\left(\mathbf{c m}^{3} / \mathbf{g}\right)$ & $V_{\text {me }}\left(\mathbf{c m}^{3} / \mathbf{g}\right)$ & $w_{\text {avg }}(\mathbf{n m})$ & $w_{\text {mi }}(\mathbf{n m})$ & $w_{\text {me }}(\mathbf{n m})$ \\
\hline \hline SC & 212.6 & 182.2 & 30.4 & 0.082 & 0.064 & 0.018 & 0.80 & 0.68 & 1.23 \\
\hline SCK1 & 1034.8 & 926.2 & 106.6 & 0.636 & 0.560 & 0.076 & 1.40 & 3.33 \\
\hline SCK2 & 1171.4 & 964.5 & 206.9 & 0.756 & 0.635 & 0.121 & 1.29 & 1.40 & 3.24 \\
\hline SCK3 & 1289.6 & 992.3 & 297.3 & 0.877 & 0.684 & 0.193 & 1.39 & 1.48 & 3.25 \\
\hline
\end{tabular}

electrolyte ions can penetrates easily in both micropores having a size of about $0.9 \mathrm{~nm}$ and in mesopores of $2.8 \mathrm{~nm}$ reacting repeatedly in various processes. In contrast to it, the larger $\mathrm{LiClO}_{4}$ ion can only diffuse through the mesopores. From this point of view the maximum specific capacitance observed for the CP54 sample is attributed to the fact that CP54 sample allowed a bigger amount of $\mathrm{LiClO}_{4}$ ions to diffuse into its mesopores. In addition, the accessibility of micropores and mesopores by electrolyte ions and the increase of the specific capacitance value is related to an increase of the oxygenated group concentration of SCK samples measured at $1709 \mathrm{~cm}^{-1}$ as the $\mathrm{KOH}$ ratio increases from 1 to 4 (as one could see in Fig. 1). The presence of oxygenated groups concentration can improve the wettablity of the AC surface, which is important in order to maximize the access of the electrolyte to the surface of AC [26].

From the data in Table 2 , it follows that the increase of the measured specific capacitance can be attributed to the increase of SSA and PSD. The presence of micropores of a size $0.9 \mathrm{~nm}$ can effectively decrease the ion-sieving effect. The CP5 samples have micropores with diameters corresponding to 1 or 2 sulfate ion diameters and allow 1 or 2 sulfide ions to reach the inner surface of the micropores. Thus, it seems that a relative range in sizes between the size of the micropores and that of the inserted ion into micropore

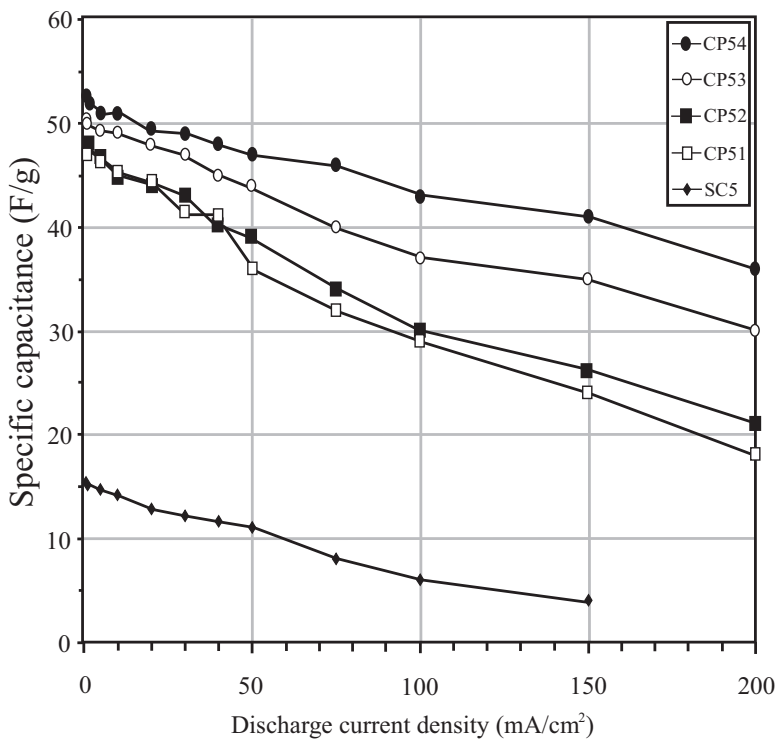

(a) is appropriate for getting a higher specific capacitance [27]. The value of the specific capacitance however measured in the experiments is lower than the expected value reported in the literature [28, 29]. This could be ascribed to a low electrosorption due to wide mesopores size. The CP5 samples have mesopores with diameter of about $2.8 \mathrm{~nm}$, which amounts to nearly six diameters of a sulfate ion. Although the multiple sulfate $\mathrm{SO}_{4}{ }^{2-}$ ions can penetrate easily inside these mesopores, the interaction between them and the walls of the pores is rather weak. Therefore, the mesopores with too wide diameter in CP5 samples was not efficient for participation in the formation of the double layer [27, 28]. This is the main cause of decreasing the specific capacitance in our case.

Fig. (4) shows $\mathrm{N}_{2}$ adsorption isotherms of the $\mathrm{CP}$ samples at $77 \mathrm{~K}$. It can be seen that their patterns are similar to the adsorption isotherms of the SCK samples shown in Fig. (2). The isotherms of all CP samples are of Type I, which is always indicative for the presence of micropores in a porous solid. As one could expect, increasing the content of the PTFE binder leads to a decrease of the amount of the absorbed $\mathrm{N}_{2}$, which results in a decrease of the SSA or the total volume of the pore in the CP samples. Thus, the lower SSA of the SCK4 samples can be explained by the fact that the adhesive PTFE binder blocks partly the pores.

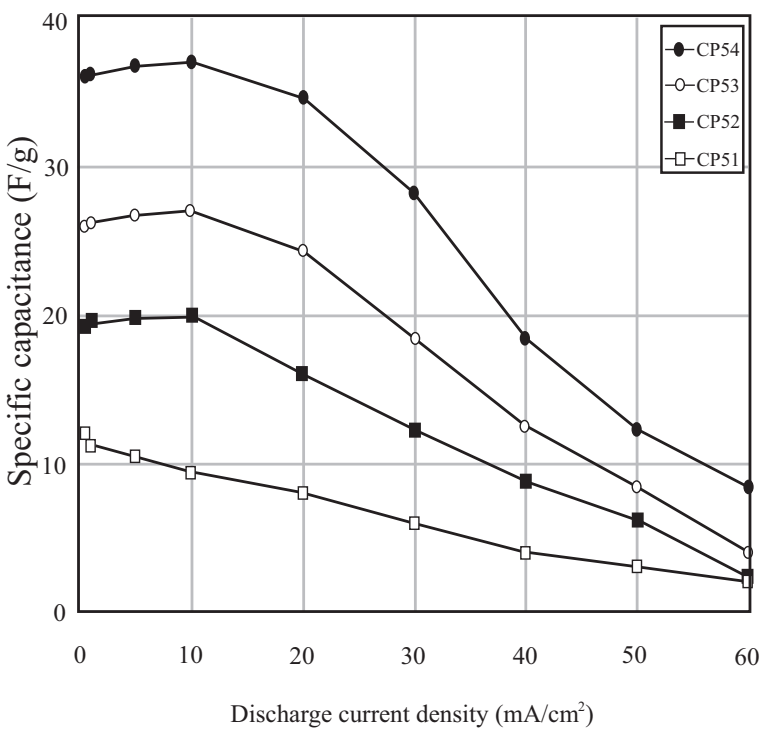

(b)

Fig. (3). The specific capacitances of the CP5 samples in: (a) aqueous electrolyte (30 wt.\% $\left.\mathrm{H}_{2} \mathrm{SO}_{4} / \mathrm{H}_{2} \mathrm{O}\right)$ and (b) organic electrolyte (1 M $\mathrm{LiClO}_{4} / \mathrm{PC}$ ), as a functions of the discharge current density and different $\mathrm{KOH}$ ratio. The labels CP51, CP52, CP53 and CP54 correspond to samples prepared from SCK1, SCK2, SCK3 and SCK4 as described in the text. 
Table 2. The Pore Characteristics of the SC and SCK with PTFE Content of 5\% and the Specific Capacitance Measured at Discharge Current Density of $0.5 \mathrm{~mA} / \mathrm{cm}^{2}$

\begin{tabular}{|c|c|c|c|c|c|c|c|c|c|c|}
\hline Sample Type & $\boldsymbol{S}_{\text {BET }}\left(\mathbf{m}^{2} / \mathbf{g}\right)$ & $\boldsymbol{S}_{\mathrm{mi}}\left(\mathbf{m}^{2} / \mathbf{g}\right)$ & $\boldsymbol{S}_{\mathrm{me}}\left(\mathbf{m}^{2} / \mathbf{g}\right)$ & $\boldsymbol{V}_{\text {total }}\left(\mathbf{c m}^{3} / \mathbf{g}\right)$ & $\boldsymbol{V}_{\mathbf{m i}}\left(\mathbf{c m}^{3} / \mathbf{g}\right)$ & $\boldsymbol{V}_{\mathbf{m e}}\left(\mathbf{c m}^{3} / \mathbf{g}\right)$ & $\boldsymbol{w}_{\text {avg }}(\mathbf{n m})$ & $\boldsymbol{w}_{\mathrm{mi}}(\mathbf{n m})$ & $\boldsymbol{w}_{\mathrm{me}}(\mathbf{n m})$ & $\mathbf{C}(\mathbf{F} / \mathbf{g})$ \\
\hline \hline SC5 & 179.2 & 150.3 & 28.9 & 0.073 & 0.059 & 0.014 & 0.72 & 0.64 & \\
\hline CP51 & 1002.6 & 897.4 & 105.2 & 0.607 & 0.541 & 0.066 & 1.09 & 0.92 & 2.83 & 47.5 \\
\hline CP52 & 1119.6 & 919.2 & 200.4 & 0.716 & 0.608 & 0.108 & 1.08 & 0.90 & 2.81 & 52.2 \\
\hline CP53 & 1221.4 & 933.9 & 287.5 & 0.763 & 0.580 & 0.183 & 1.06 & 0.89 & 2.81 & 58.4 \\
\hline CP54 & 1408.2 & 960.4 & 447.8 & 0.897 & 0.647 & 0.223 & 1.04 & 0.88 & 2.80 & 64.1 \\
\hline
\end{tabular}

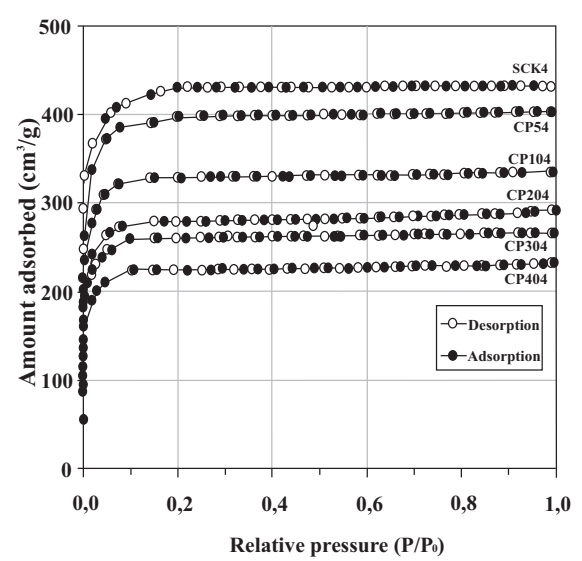

Fig. (4). $\mathrm{N}_{2}$ adsorption isotherms of the CP samples with different content of the PTFE binder at $77 \mathrm{~K}$. The samples with PTFE content of $10 \%, 20 \%, 30 \%$ and $40 \%$ were labeled accordingly as CP104, CP204, CP304 and CP404.

The SSA and PSD characteristics presented in Table $\mathbf{3}$ correspond to the SCK4 samples with varying PTFE content. Also shown in Table 3 are the values of the specific capacitance measured at discharge current density of of 0.5 $\mathrm{mA} / \mathrm{cm}^{2}$ in $\mathrm{H}_{2} \mathrm{SO}_{4}$. It can be seen that the SSA and PSD were reduced with increasing PTFE content from 5 to $40 \%$. Higher fractions of the binder lead to a stronger occlusion of PSD. 5\% of PTFE was found to be sufficient, which is the lowest of PTFE reported in the literature [30-32]. Fig. (5a, b) show the variation of SSA and the total volume of the micropores and the mesopores with PTFE content, respectively. It can be seen that the SSA and the total volume in both the micropores and the mesopores decrease with increasing of the PTFE content. The decrease of the slope of the curves that show the variation of both the SSA and the total volume is larger for the micropores than in for the mesopores. This means that more micropores on the surface of SCK 4 samples were blocked by PTFE while the blockage of the mesopores existed in the interior of the samples is significantly less.

The effects of the PTFE binder content are then explored by analyzing the microtextural structure of the surface of the CP samples. Fig. (6) shows the SEM images of the SCK4 sample as well as of the CP samples (CP54, CP104, CP204, CP304 and CP404) with different content of the PTFE binder. As the latter increases in the range $5-40 \%$ the pores in the surface decrease. The reason for this behavior is attributed to to the adhesion of the PTFE binder to the SCK4 particles one by one to form agglomerates. The amount of such agglomerates increases with the PTFE content. The CP samples containing $10-30 \%$ the PTFE binder have a surface with a high concentration of small pits. Highest fractions $(40 \%)$ of the binder lead to even stronger blockage of the pores. Eventually, as the image of the CP404 sample shows, at higher concentrations of the binder pores are not seen at all.

Fig. (7) shows the variation of the specific capacitance in the samples with 30 wt. $\% \mathrm{H}_{2} \mathrm{SO}_{4} / \mathrm{H}_{2} \mathrm{O}$ and $1 \mathrm{M} \mathrm{LiClO}_{4} / \mathrm{PC}$ as a function of the discharge current density for different values of the $\mathrm{KOH}$ ratio in the $\mathrm{CP}$ samples. The specific capacitance decreases with increasing of the PTFE content in $\mathrm{H}_{2} \mathrm{SO}_{4}$ or $\mathrm{LiClO}_{4}$ electrolyte. This decrease of the specific capacitance was confirmed by the measured SSA and PSD and observed SEM. Further, a decrease of the specific capacitance is smaller in $\mathrm{LiClO}_{4}$ electrolyte than in $\mathrm{H}_{2} \mathrm{SO}_{4}$ electrolyte in the low discharge current density range $(<50$ $\left.\mathrm{mA} / \mathrm{cm}^{2}\right)$. This can be explained that as shown in Table 3, the presence of micropores with diameter up to $0.9 \mathrm{~nm}$ can only provides pathways for $\mathrm{H}_{2} \mathrm{SO}_{4}$ electrolyte ions, while mesopores can provide pathways for $\mathrm{LiClO}_{4}$ electrolyte ions.

Table 3. The Pore Characteristics of the SCK4 with Varying PTFE Content and the Specific Capacitance Measured at Discharge Current Density of $0.5 \mathrm{~mA} / \mathrm{cm}^{2}$

\begin{tabular}{|c|c|c|c|c|c|c|c|c|c|c|}
\hline Sample Type & $\boldsymbol{S}_{\text {BET }}\left(\mathbf{m}^{2} / \mathbf{g}\right)$ & $\boldsymbol{S}_{\text {mi }}\left(\mathbf{m}^{2} / \mathbf{g}\right)$ & $\boldsymbol{S}_{\text {me }}\left(\mathbf{m}^{2} / \mathbf{g}\right)$ & $V_{\text {total }}\left(\mathbf{c m}^{3} / \mathbf{g}\right)$ & $V_{\text {mi }}\left(\mathbf{c m}^{3} / \mathbf{g}\right)$ & $V_{\text {me }}\left(\mathbf{c m}^{3} / \mathbf{g}\right)$ & $w_{\text {avg }}(\mathbf{n m})$ & $w_{\text {mi }}(\mathbf{n m})$ & $w_{\text {me }}(\mathbf{n m})$ & $\mathbf{C}(\mathbf{F} / \mathbf{g})$ \\
\hline \hline SCK4 & 1497.5 & 1020.8 & 476.7 & 0.973 & 0.727 & 0.246 & 1.30 & 1.40 & 3.21 & \\
\hline CP54 & 1408.2 & 960.4 & 447.8 & 0.897 & 0.647 & 0.223 & 1.04 & 0.88 & 2.80 & 64.1 \\
\hline CP104 & 1265.4 & 848.6 & 416.8 & 0.776 & 0.563 & 0.213 & 1.06 & 0.83 & 2.74 & 60.4 \\
\hline CP204 & 1194.4 & 794.5 & 399.9 & 0.672 & 0.491 & 0.181 & 0.98 & 0.80 & 2.70 & 56.2 \\
\hline CP304 & 1112.8 & 717.4 & 395.4 & 0.601 & 0.447 & 0.154 & 0.96 & 0.74 & 2.68 & 50.6 \\
\hline CP404 & 995.6 & 612.6 & 383.0 & 0.518 & 0.391 & 0.127 & 0.92 & 0.70 & 2.65 & 48.9 \\
\hline
\end{tabular}




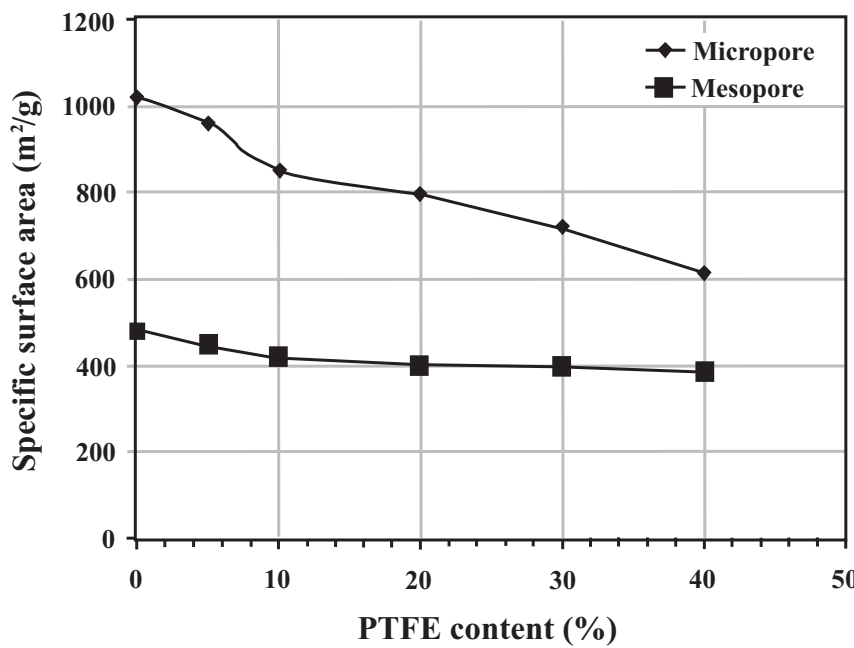

(a)

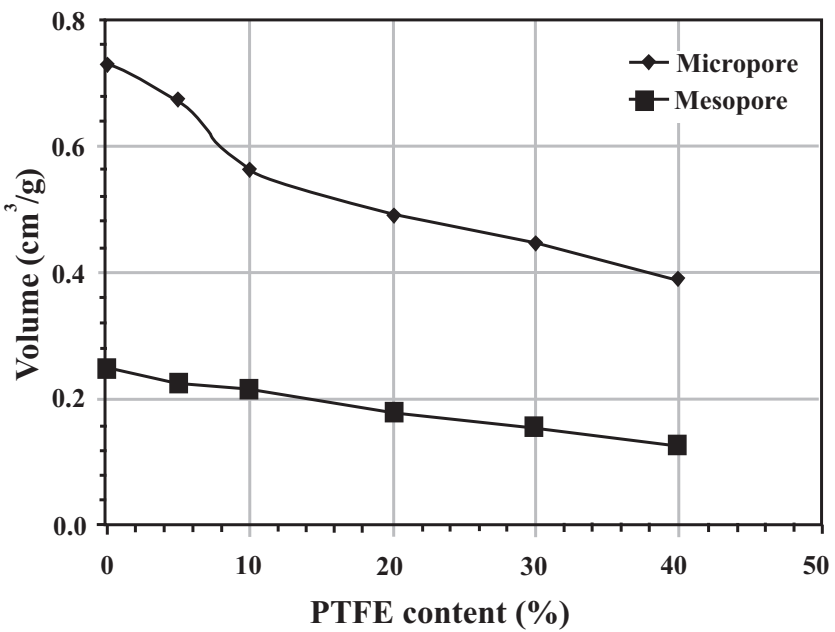

(b)

Fig. (5). The variation of SSA and the total volume of micropores and mesopores with PTFE content.

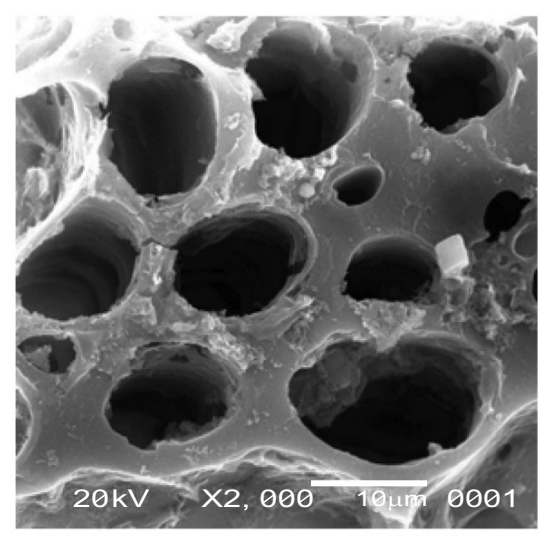

(a)

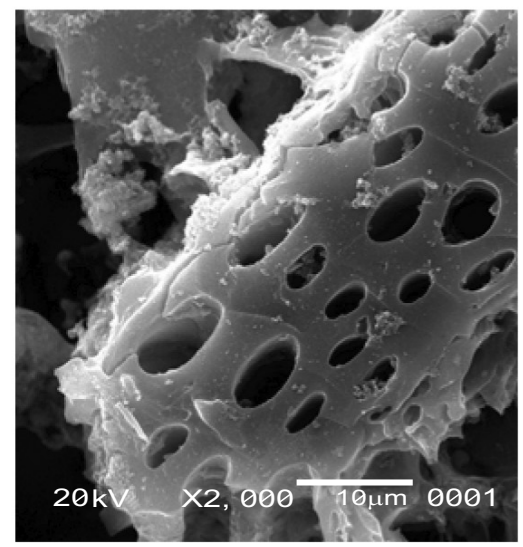

(d)

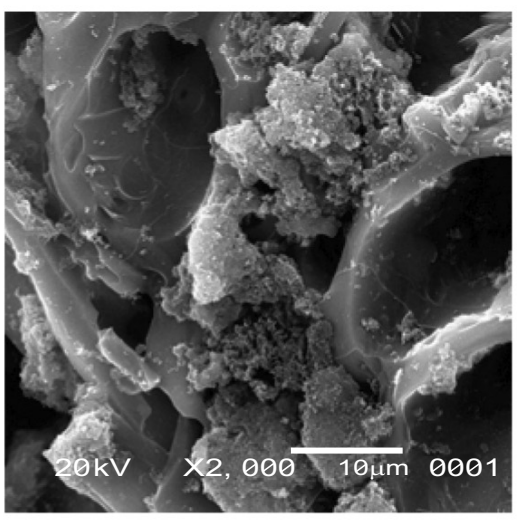

(b)

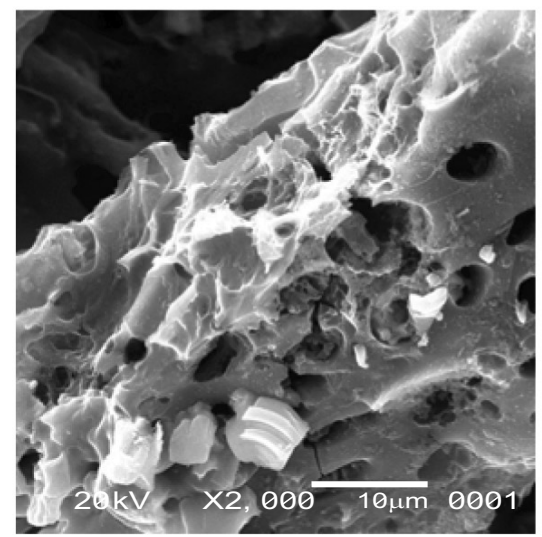

(e)

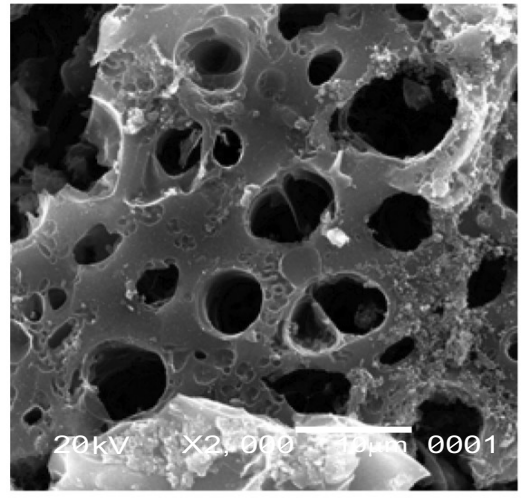

(c)

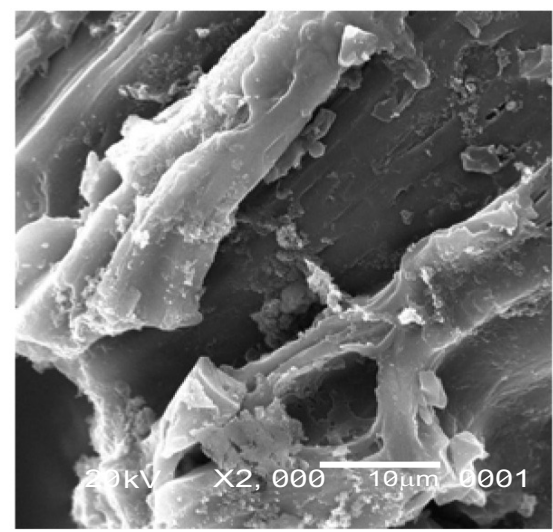

(f)

Fig. (6). SEM images of the samples: (a) SCK4, (b) CP54, (c) CP104, (d) CP204, (e) CP304 and (f) CP404. The samples CP104, CP204, CP304 and CP404 were prepared using SCK4 compound and PTFE content of 10\%, 20\%, 30\% and 40\%, respectively. 


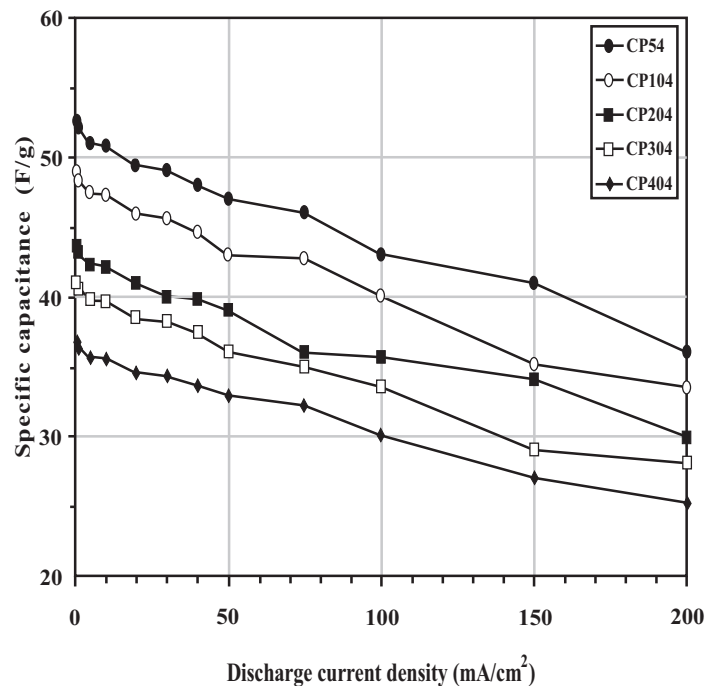

(a)

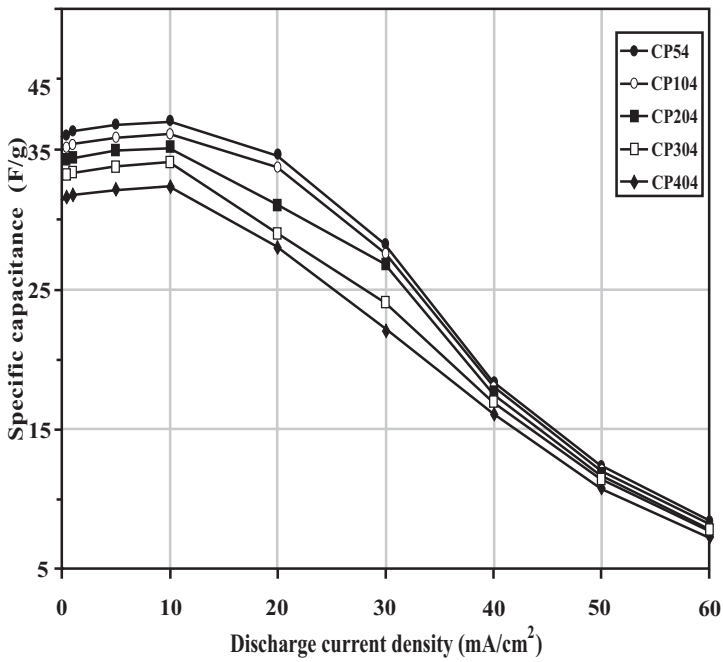

(b)

Fig. (7). The specific capacitance of the $\mathrm{CP}$ samples in: (a) aqueous electrolyte $\left(30 \mathrm{wt} . \% \mathrm{H}_{2} \mathrm{SO}_{4} / \mathrm{H}_{2} \mathrm{O}\right)$ and (b) organic electrolyte (1 M $\mathrm{LiClO}_{4} / \mathrm{PC}$ ), as a function of the discharge current density and different content of the PTFE binder. The labels CP104, CP204, CP304 and CP404 correspond to samples produced using SCK4 compound and PTFE content of $10 \%, 20 \%, 30 \%$ and $40 \%$, respectively.

\section{CONCLUSIONS}

In this feasibility study we presented a novel and very promising electrode material for EDLC. It is based on the sago waste, which is abundant in Indonesia.

The AC films prepared from this material have a microporous structure with a relatively high percentage of small mesopores that depends on the $\mathrm{KOH}$ to charcoal ratio. An increase of the latter leads to the formation of bigger number of small mesopores than the number of micropores and eventually causes an increase of the total SSA. In the studied samples the SSA was in the range from 212 to $1498 \mathrm{~m}^{2} / \mathrm{g}$.

Another important technological parameter is the content of the PTFE binder. The experimental results show that the SSA of the SCK4 samples decreases when the content of the PTFE increases due to the reduction of the number of micropores. Such explanation is confirmed by the microtextural SEM images of the $\mathrm{CP}$ samples. The specific capacitance of the samples was in the range from 16 to 64 $\mathrm{F} / \mathrm{g}$. The role of mesopores and micropores is important for controlling the value of the capacitance in EDLCs. Therefore, for realization of an electrode material made from the CP samples, the amount of the binder must be minimized in order to maximize the specific capacitance.

\section{ACKNOWLEDGEMENT}

This research was supported by the fund of the Directorate of Higher Education, Department of Education, Republic of Indonesia. The authors would like to thank Mr. Sudirman from the Center for Technology of Nuclear Industry Material (PTBIN), Nation Atomic Power (BATAN) for kindly helping to prepare the ACs films and the porous polypropylen membrane for the separator.

\section{REFERENCES}

[1] An KH, Jeong SY, Hwang HR, Lee YH. Enhanced sensivity of a gas sensor incorporating single-walled carbon nanotubepolypyrrole nanocomposites. Adv Mater 2004; 16: 1005-9.
[2] Nakanishi A, Tamai M, Kawasaki N, Nakamura T, Araki M, Tanada S. Characterization of water adsorption onto carbonaceous material produced from food waste. J Colloid Interf Sci 2002; 255: 59-63.

[3] Tien CP, Liang WJ, Kuo PL, Teng HS. Electric double layer capacitor with gelled polymer electrolytes based on poly(ethylene oxide) cured with poly (propylene oxide) diamines. Electrochim Acta 2008; 53: 4505-11.

[4] Subramanian V, Luo C, Stephan AM, Nahm KS, Thomas S, Wei B. Supercapacitor from activated carbon derived from banana fibers. J Phys Chem 2007; 111: 7527-31.

[5] Endo M, Kim Y, Osawa K, Ishii K, Inoue T, Nomura T, Miyashita N, Dresselhaus MS. High capacitance EDLC using a carbon material obtained by carbonization of PVDC. Electrochem SolidState Lett 2003; 6: A23-A26.

[6] Mastragostino M, Arbizzani C, Soavi F. Conducting polymers as electrode materials in supercapacitors. Solid State Ionic 2002; 148: 493-8.

[7] Guiven L, Wu D, Fu R, Zhang Z, Su Z. Electrochemical properties of conductive filler/carbon aerogel composites as electrodes of supercapacitor. J Non-Cryst Solids 2008; 354: 4567-71.

[8] Nakagawa H, Shudo A, Miura K. High capacity electric double layer capacitor with high density actived carbon. J Electrochem Soc 2000; 147 : 38-42.

[9] Frackowiak E, Metenier K, Bertagna V, Beguin F. Supercapacitor electrodes from multiwalled carbon nanotubes. Appl Phys Lett 2000; 77: 2421-23.

[10] An KH, Kim WS, Park YS, et al. Supercapacitors using singlewalled carbon nanotube electrodes. Adv Mater 2001; 13: 497-500.

[11] Aripin H, Jahiding M, Elys. Proceedings of $3^{\text {rd }}$ Kentingan Physics Forum, Solo, Indonesia, September 2005.

[12] Aripin H. Characterization and conductivity behaviour of magnetic activated carbon (MAC) from $\mathrm{FeCl}_{2} .4 \mathrm{H}_{2} \mathrm{O}$ containing carbon. J Solid State Sci Tech Lett 2006; 13: 19-22.

[13] Yoon S, Lee J, Hyeon T, Oh S. Electric double layer capacitor of a new mesoporous carbon. J Electrochem Soc 2000; 147: 2507-12.

[14] Vikineswary S, Shim YL, Thambirajah JJ, Blake-Brough N Possible microbial utilization of sago processing wastes. Resour Conserv Recycl 1994; 11: 289-96.

[15] Barbieri O, Hahn M, Herzog A, Kotz R. Capacitance limits of high surface area activated carbons for double layer capacitors. Carbon 2005; 43: 1303-10.

[16] Brunauer S, Emmett PH, Teller E. Adsorption of gases in multimolecular layers. J Am Chem Soc 1938; 60: 309-14.

[17] Cole MW, Holter NS, Pfeifer P. Henry's law of adsorption on a fractal surface. Phys Rev 1986; B33: 8806-10.

[18] Dubinin MM, Radushkevich LV. Equation of the characteristic curve of activated charcoal. Chem Zentr 1947; 1: 875-90. 
[19] Conwey BE. Electrochemical supercapacitor, scientific fundamentals and technological application. New York: Kluwer Academic, Plenum Publisher 1993.

[20] Demiral H, Demiral I, Tumsek F, Karabacokoglu L. Pore structure of activated carbon prepared from hazelnut baggase. Surface Interf Anal 2008; 40: 616-9.

[21] Cheng CH, Lehmann J, Thies JE, Burton SD, Engelhard MH. Oxidation of black carbon by biotic and abiotic process. Org Geochem 2006; 37: 1477-88.

[22] Rouquerol J, Avnir D, Fairbridge CW, et al. IUPAC Recommendations: Recommendation for the characterization of porous solids. Pure Appl Chem 1994; 66: 1739-58.

[23] Tseng RL, Tseng SK. Pore structure and adsorption performance of the $\mathrm{KOH}$ activated carbon prepared from corncob. J Coloid Interf Sci 2005; 287: 428-37.

[24] Endo M, Takeda T, Kim YJ, Koshiba K, Ishii K. High power electric double layer capacitor (EDLC): from operating principle to pore size control in advanced activated carbon. Carbon Sci 2001; 1: $117-28$.

[25] Lazano-Castelo D, Cazorla-Amoros D, Shirashi A, Kurihara S, Oya A. Influence of pore structure and surface chemistry on electric double layer capacitance in non-aqueous electrolyte. Carbon Sci 2003; 41: 1765-75.

[26] Babel K, Jurewicz K. KOH activated carbon fabric as supercapacitor material. J Phys Chem Solids 2004; 65: 275-80.

[27] Lin C, Ritter JA, Popov BN. Correlation of double layer capacitance with the pore structure of sol gel derived carbon xerogels. J Electrochem Soc 1999; 146: 3639-43.

[28] Frackowiak E. Carbon material for supercapacitor application. Phys Chem Chem Phys 2007; 9: 1774-85.

[29] Pandolfo AG, Hollenkamp AF. Carbon properties and their role in supercapacitors. J Power Sources 2006; 157: 11-27.

[30] Park JH, Shin OO, Jin KH, Kim JH. An electrochemical based on a $\mathrm{Ni}(\mathrm{OH})_{2} /$ activated carbon composite electrode. Electrochem Solid State Lett 2002; 5: H7-H10.

[31] Ramani M, Haran BS, White RE, Popop BN, Arsov L. Studies on activated carbon capacitor materials loaded with different amount of rutherium oxide. J Power Sources 2001; 93: 209-14.

[32] Wei YJ, Fang B, Iyasa S, Kumagai M. A novel electrode material for electric double layer capacitor. J Power Sources 2005; 141: 386-91.

(C) Aripin et al.; Licensee Bentham Open.

This is an open access article licensed under the terms of the Creative Commons Attribution Non-Commercial License (http://creativecommons.org/licenses/ by$\mathrm{nc} / 3.0 /$ ) which permits unrestricted, non-commercial use, distribution and reproduction in any medium, provided the work is properly cited. 